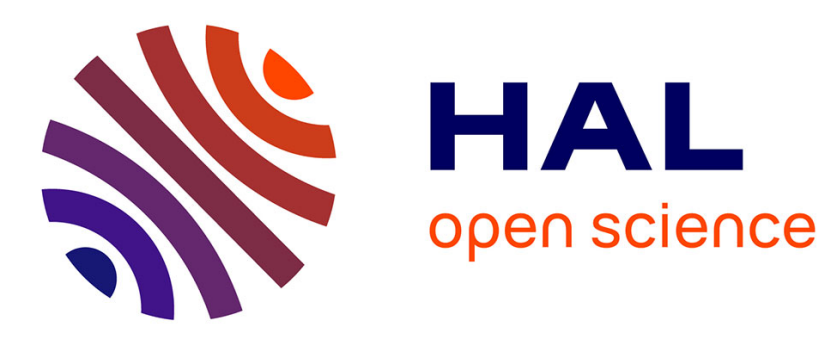

\title{
Slow down, you move too fast!
}

Jorryt van Bommel, Hanna Palmér

\section{To cite this version:}

Jorryt van Bommel, Hanna Palmér. Slow down, you move too fast!. CERME 10, Feb 2017, Dublin, Ireland. hal-01938908

\section{HAL Id: hal-01938908 https://hal.science/hal-01938908}

Submitted on 29 Nov 2018

HAL is a multi-disciplinary open access archive for the deposit and dissemination of scientific research documents, whether they are published or not. The documents may come from teaching and research institutions in France or abroad, or from public or private research centers.
L'archive ouverte pluridisciplinaire HAL, est destinée au dépôt et à la diffusion de documents scientifiques de niveau recherche, publiés ou non, émanant des établissements d'enseignement et de recherche français ou étrangers, des laboratoires publics ou privés. 


\title{
Slow down, you move too fast!
}

\author{
Jorryt van Bommel ${ }^{1}$ and Hanna Palmér ${ }^{2}$ \\ ${ }^{1}$ Karlstad University, Sweden; jorryt.vanbommel@kau.se \\ ${ }^{2}$ Linnaeus University, Sweden; hanna.palmer@lnu.se
}

Keywords: Abstraction, combinatorics, representations, pre-school.

\section{Short description of the research topic and theoretical framework}

The focus of this poster is on the links between representations and solutions when 6-year-olds work on combinatorial tasks. The task can be explained as follows: In how many ways can three bears sit on a sofa?

Studies of young children's representations often focus on informal and formal representations. Abstraction is often perceived as a goal and teachers often value when young children use abstract representations. Heddens (1986) introduced semi-concrete and semi-abstract as connections between concrete (objects) and abstract (signs) representations. He referred to representations of real situations, for example, pictures of real items, as semi-concrete, whereas he referred to symbolic representations of concrete items, where the symbols or pictures do not look like the objects they represent, as semi-abstract. Connected to the task presented above, concrete implies real bears and a sofa, semi-concrete implies images of (resembling) bears, semi-abstract implies a symbolic, not resembling, representation of the bears and abstract implies the use of formal signs. As for the concrete level, the 'real' bears can be replaced by three play-bears, or by engaging in a role-play, enacting the situation. In both semi-concrete and semi-abstract representations, the colours of the bears and their symbols are often kept identical.

When conducting the combinatorial task in 13 pre-school classes in Sweden (125 children, age 6), children showed different levels of abstraction in their solutions of the problem. In a previous paper we problematized the apparent relation between the level of abstraction and the number of duplicate solutions. Surprisingly we found that the children who used semi-concrete representations in their documentations were more systematic in the process of finding solutions with less duplication than the children who used semi-abstract representations. We argued that a more abstract level seemed to reduce the problem from bears on a sofa to putting three coloured dots on a paper. It seemed that children moved too fast to the next level of abstraction. Internalisation of the problem had not occurred yet which led to a reduction of the problem as described above. Simultaneously, we also concluded that documentation within the semi-concrete level was very time-consuming for children, as it takes a lot of time for the children to draw bears (Palmér \& van Bommel, 2017).

\section{Methodology}

How could we slow down these children without slowing down the process of documentation? An application was especially designed to let children work on the semi-concrete level, and simultaneously, the time-consuming issue of drawing the bears was taken into account. The aim of the application was to provide an opportunity to develop an understanding of combinatorics and its 
systematisation by letting children work within the semi-concrete level. The design-principles for the application concerned a possibility to adjust the level of the problem, resulting in a choice of the number of bears and the size of sofa. It also resulted in the possibility to save solutions as well as to offer an insight to all outcomes. By doing so, we wanted to explore the semi-concrete level more explicitly and focus on the learning opportunities this level of abstraction can offer the children.

During the autumn of 2016, 6-year-olds (about 60) from different preschool-classes have tested the application. Our reflections concern the learning opportunities created by using the digital form of documentation (in addition to the paper and pencil forms). After using the application, we let the children work on similar combinatorial tasks but only by using paper and pencil.

\section{Preliminary results}

Our preliminary results show that the children who have worked with the application do not document as many duplicates when using semi-abstract representations as the children in our previous study (Palmér \& van Bommel, in press). Additionally, we see an increase in the systematic way they organise and search for solutions. These first results of the study also indicate that the children indeed develop significant skills when working within the semi-concrete level, for instance they seem to have obtained a good understanding of what the concept different combinations entails. A special note has to be made towards the possibility to adjust the level of the task in the application. For example, some children explored the situations of two bears on a three-seat sofa and four-seat sofas with different number of bears. Such explorations led to discussions of similarities between two and three bears on a three-seat sofa and mathematical aspects of the tasks were discussed at another level compared to paper and pencil lessons.

\section{References}

Heddens, J. W. (1986). Bridging the gap between the concrete and the abstract. The Arithmetic Teacher, 33(6), 14-17.

Palmér, H. \& van Bommel, J. (2017). Exploring the role of representations when young children solve a combinatorial task. In J. Häggström, E. Norén, J. van Bommel, J. Sayers, O. Helenius, \& Y. Liljekvist (Eds.), Proceedings of MADIF 10. The Tenth Swedish Mathematics Education Research Seminar (pp.47-55). Karlstad, Sweden: SMDF.

\section{Poster can be downloaded at:}

https://www.kau.se/files/2017-02/cerme_vanBommelPalmér_Slowdownyoumovetoofast.pdf 